\title{
Reverse Correlation between Urine Nitric Oxide Metabolites and Insulin Resistance in Patients with Type 2 Diabetes Mellitus
}

\author{
SOICHI KURIOKA, Kunio KOSHIMURA, Yoshio MURAKAMI, Masateru NISHIKI aNd YuZURU KATO
}

First Division, Department of Medicine, Shimane Medical University, Izumo 693-8501, Japan

\begin{abstract}
We studied the possible relationship between nitric oxide (NO) production and insulin resistance in patients with type 2 diabetes mellitus. Urine NO metabolites (NOx) were measured as an index for NO production by HPLC combined with a Cd column, Griess reaction and a spectrophotometer in 403 healthy control subjects and 102 hospitalized patients with type 2 diabetes. Glucose infusion rate (GIR) was measured as a reverse index for insulin resistance by euglycemic glucose clamp study using an artificial pancreas in 20 of 102 diabetic patients. Urine NOx was lower in the patients with type 2 diabetes than in healthy control subjects (mean $\pm \mathrm{SE}: 3.18 \pm 0.02$ versus $3.25 \pm 0.01 \log [\mu \mathrm{mol} / \mathrm{gCr}], \mathrm{p}<0.01)$. Urine NOx was correlated with body mass index (BMI) in 102 diabetic patients $(\mathrm{r}=-0.372, \mathrm{p}<0.001)$, but not related to either age, sex, fasting plasma glucose, $\mathrm{HbA}_{\mathrm{lc}}$ or blood pressure. Urine NOx was correlated with GIR independent of BMI in 20 diabetic patients $(r=0.774, P<0.0001)$. These findings suggest that NO production is closely related with insulin resistance in patients with type 2 diabetes.
\end{abstract}

Key words: Nitric oxide, Insulin resistance, Type 2 diabetes mellitus, Urine, Euglycemic glucose clam

(Endocrine Journal 47: 77-81, 2000)

INSULIN resistance is one of the major pathological conditions in type 2 diabetes mellitus. Hyperinsulinemia induced by sustained hyperglycemia deteriorates insulin-mediated glucose transport in the skeletal muscle. Hyperglycemia itself is considered a critical factor for insulin resistance. It is also suggested that insufficient blood flow in the skeletal muscle is associated with insulin resistance $[1,2]$. Nitric oxide (NO) is known to be a physiological vasodilator generated in vascular endothelial cells [3]. Several lines of evidence suggest a close relationship between insulin resistance and hypertension [4-8]. It was reported that L-arginine, a natural precursor of NO, improved insulin resistance $[9,10]$. These findings suggest that reduced NO production may

Received: September 6, 1999

Accepted: November 17, 1999

Correspondence to : Kunio KOSHIMURA M.D., Ph.D., First Division, Department of Medicine, Shimane Medical University, Izumo 693-8501, Japan. contribute, at least partly, to insulin resistance in type 2 diabetes. In the present study, we examined the possible relationship between urine NO metabolites (NOx) levels as an index for NO production and glucose infusion rate (GIR) under euglycemic clamp as a reverse index for insulin resistance in patients with type 2 diabetes.

\section{Research Design and Methods}

\section{Subjects}

We examined 403 healthy control subjects (164 males and 239 females) and 102 hospitalized patients with type 2 diabetes ( 71 males and 31 females). Mean ( $\pm \mathrm{SD})$ age was $50 \pm 15 \mathrm{yr}$ and $58 \pm 13 \mathrm{yr}$, respectively. The healthy control subjects did not show any abnormality in blood pressure, body mass index (BMI), serum indices for hepatic function (total protein, albumin, GOT, GPT and LDH) and 
renal function (BUN, creatinine, uric acid, $\mathrm{Na}, \mathrm{K}$ and $\mathrm{Cl}$ ) and urinalysis. Blood pressure and serum indices for hepatic and renal functions were normal in all the patients with type 2 diabetes. Mean $( \pm S D)$ values of fasting plasma glucose, $\mathrm{HbA}_{1 \mathrm{c}}$ and body mass index (BMI) were $6.2 \pm 1.0 \mathrm{mmol} / 1,6.5 \pm 1.0 \%$ and $23.5 \pm$ $4.3 \mathrm{~kg} / \mathrm{m}^{2}$, respectively.

\section{NO metabolites (NOx) assay}

NO production was estimated by measuring NO metabolites $\left(\mathrm{NOx}=\mathrm{NO}_{2}{ }^{-}+\mathrm{NO}_{3}{ }^{-}\right)$in the urine. Urine samples were collected in the early morning after an overnight fast. Sodium azide was added to the samples, which were then stored at $4^{\circ} \mathrm{C}$ until assayed. Urine NOx was measured by NOx analyzing HPLC system (ENO-10, Eicom, Kyoto, Japan) as described previously [11], and corrected by creatinine concentration. All values were expressed on a logarithmic scale as described previously [11].

\section{Euglycemic clamp study}

Insulin resistance was evaluated by euglycemic clamp study performed according to the method of DeFronzo et al. [12], using the artificial pancreas (STG-22, Nikkiso Co., Tokyo, Japan) as reported previously [13]. The study was carried out in 20 patients with type 2 diabetes selected at random from 102 hospitalized diabetic patients. Informed consent was obtained from all patients who participated in the study. After overnight fasting, indwelling catheters were inserted into both antecubital veins at 9 am, Regular human insulin (Eli Lilly Co., Indianapolis, IN, U.S.A) was infused into an antecubital vein at a dose of $800 \mathrm{mU}$ over $10 \mathrm{~min}$ as a priming. This was followed by a 120 -min constant infusion of insulin at the flow rate of $40 \mathrm{mU} / \mathrm{m}^{2} / \mathrm{min}$. Blood glucose levels were monitored and automatically maintained at the fasting level of $5.5 \mathrm{mmol} / 1$ by $10 \%$ glucose infusion at a flow rate which was corrected and recorded every minute. The steady-state glucose infusion rate was obtained between 90 and 120 min after the start of the constant insulin infusion. The mean infusion rate of glucose during the last $30 \mathrm{~min}$ was presented as the glucose infusion rate (GIR), a reverse index for insulin resistance.

\section{Statistical analysis}

Statistical differences between two groups were evaluated by unpaired Student's t test. Regression analysis was performed by the least square method. A probability of $\mathrm{P}<0.05$ was considered statistically significant.

\section{Results}

Urine $\mathrm{NO}$ metabolites $\left(\mathrm{NOx}=\mathrm{NO}_{2}{ }^{-}+\mathrm{NO}_{3}{ }^{-}\right)$were predominantly $\mathrm{NO}_{3}{ }^{-}$in both healthy control subjects and the patients with type 2 diabetes mellitus. The mean $( \pm \mathrm{SE})$ values of logarithmic urine NOx in 403 healthy control subjects were $1.55 \pm 0.02 \mathrm{log}$ $[\mu \mathrm{mol} / \mathrm{gCr}]$ for $\mathrm{NO}_{2}{ }^{-}, 3.23 \pm 0.01 \log [\mu \mathrm{mol} / \mathrm{gCr}]$ for $\mathrm{NO}_{3}{ }^{-}$and $3.25 \pm 0.01 \log [\mu \mathrm{mol} / \mathrm{gCr}]$ for $\mathrm{NOx}$, respectively. Urine NOx was lower in 102 patients with type 2 diabetes than in the healthy control subjects (mean \pm SE: $3.18 \pm 0.02 \log [\mu \mathrm{mol} / \mathrm{gCr}], \mathrm{P}<$ 0.01 ) (Fig. 1). There was a reverse correlation be-

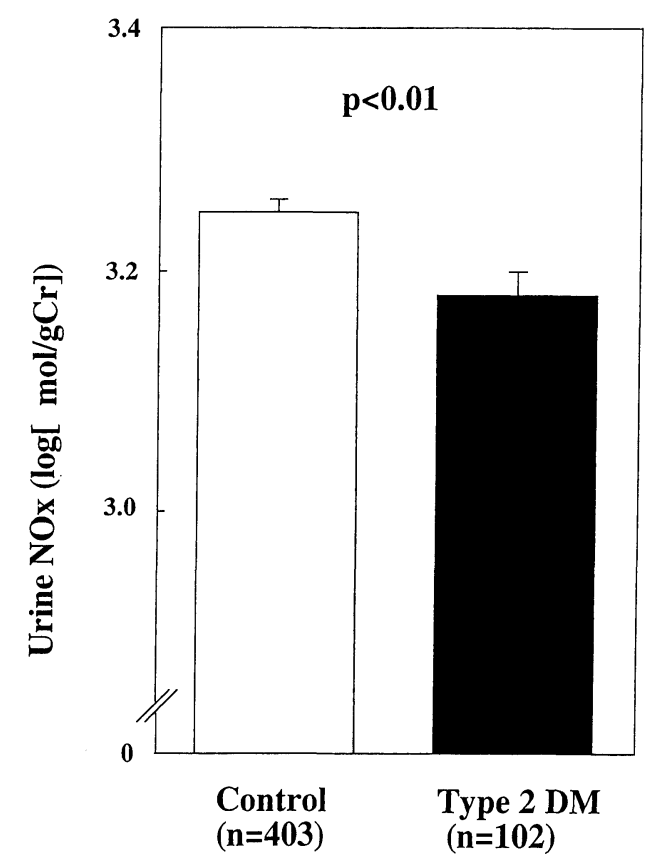

Fig. 1. Mean $( \pm S E)$ urine NOx levels in 403 healthy control subjects and 102 patients with type 2 diabetes mellitus. Urine NOx levels were expressed on a logarithmic scale. There was a significant difference $(\mathrm{P}<0.01)$ between the two groups. 
tween urine NOx and BMI $(\mathrm{r}=-0.372, \mathrm{P}<0.001)$ (Fig. 2). Urine NOx was not related to age, sex, fasting plasma glucose, $\mathrm{HbA}_{1 \mathrm{c}}$, systolic blood pressure or diastolic blood pressure in these diabetic patients (Table 1).

Mean ( $\pm \mathrm{SE})$ values of GIR were lower in 20 patients with type 2 diabetes than in 7 hospital control subjects $(5.4 \pm 0.4$ versus $8.4 \pm 0.5 \mathrm{mg} / \mathrm{kg} / \mathrm{min}$, $\mathrm{P}<0.001)$. Urine NOx was well correlated with GIR in these patients with type 2 diabetes $(r=0.774$, $\mathrm{P}<0.0001$ ) independently of BMI (Fig. 3).
Table 1. Correlation between clinical characteristics and urine NOx in 102 patients with type 2 diabetes mellitus.

\begin{tabular}{lcc}
\hline & $\mathrm{r}$ & $\mathrm{p}$ \\
\hline Sex & - & 0.34 \\
Age & 0.137 & 0.17 \\
FPG & 0.032 & 0.75 \\
HbA $_{1 \mathrm{c}}$ & 0.013 & 0.89 \\
Systolic Blood Pressure & 0.052 & 0.60 \\
Diastolic Blood Pressure & 0.048 & 0.63
\end{tabular}

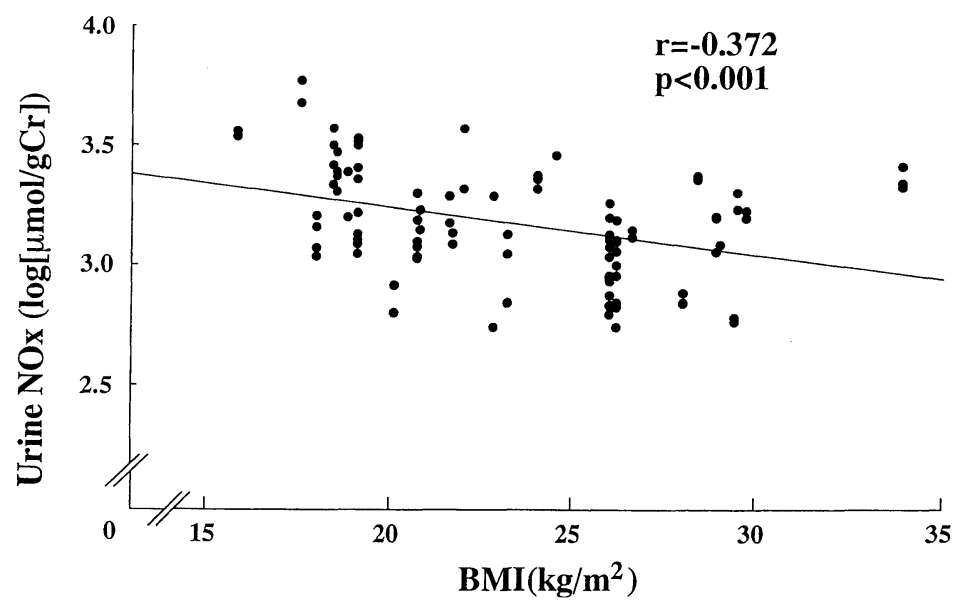

Fig. 2. Correlation between urine NOx levels and BMI in 102 patients with type 2 diabetes mellitus. There was a reverse correlation $(r=-0.372, P<0.001)$ between them.

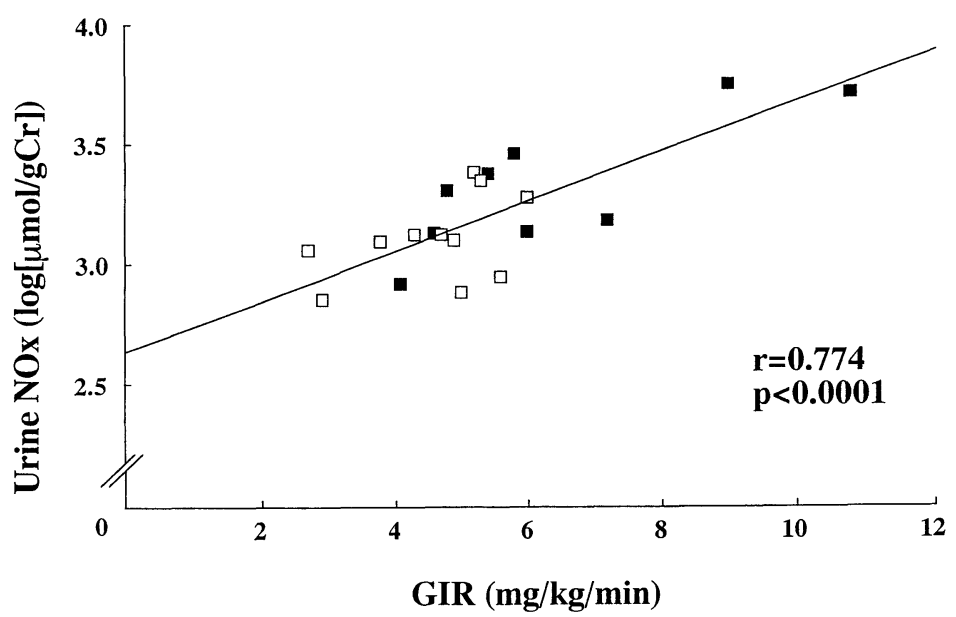

Fig. 3. Correlation between urine NOx levels and GIR in 20 patients with type 2 diabetes mellitus. There was a significant correlation $(\mathrm{r}=0.774, \mathrm{P}<0.0001)$ between them. Open and closed squares indicate diabetic patients with BMI $\geq 26.0$ $(n=11)$ and those with BMI $<26.0(n=9)$, respectively. 


\section{Discussion}

The present study showed that the mean urine NOx levels were lower in the patients with type 2 diabetes than in healthy control subjects, and that urine NOx was correlated with GIR in these diabetic patients. Since GIR is a reverse index for insulin resistance, these findings suggest a reverse correlation between urine NOx and insulin resistance in the patients with type 2 diabetes.

Since NO is rapidly metabolized, direct measurement of NO in vivo is extremely difficult. $\mathrm{NO}$ is rapidly oxidized to nitrite and then to nitrate by oxygenated hemoglobin, molecular oxygen or superoxide anions, and excreted into the urine [14]. Therefore, we measured urine nitrite and nitrate excretion as an index for NO production in the present study.

NO is produced by constitutive NO synthase in vascular endothelium and neuronal cells, or by inducible NO synthase in macrophage, neutrophils and glia cells. The subjects were clinically free from infection and trauma in the present study, and it was assumed that NO was produced predominantly by constitutive NO synthase in the subjects examined. Our findings suggest that NO production is reduced in insulin resistant diabetic patients. The reduced NOx in these patients with type 2 diabetes was not explained by sex and age since these factors did not affect urine NOx levels [11].

Recently, it was reported that L-arginine, a natural precursor of NO, improved insulin resistance $[9,10]$. These results suggest that NO may be involved in insulin resistance. NO plays an important role in regulating vascular tone, inhibiting platelet adhesion and aggregation, and protection from vasospasm and thrombosis $[15,16]$. Acetylcholine is known to stimulate NO synthesis in the endothelium [3]. Since the stimulating effect of acetylcholine on forearm blood flow is decreased in diabetic patients [17], it is speculated that NO production is impaired in diabetic patients.

As shown in the present study, urine NOx was reversely correlated with BMI that is reversely related with GIR [18]. It is noted that there was a closer correlation between urine NOx and GIR independently of BMI. These data suggest that reduced urine NOx is primarily associated with GIR in these diabetic patients. Furthermore, insulin resistance in essential hypertension was observed independently of obesity [5].

Since insulin has a trophic effect on vascular tissues [19], hyperinsulinemia is a critical factor for atherosclerosis that induces blood flow insufficiency in the skeletal muscle. It is suggested that NO synthesis is deteriorated in atherosclerotic vessels [20]. NO is reported to inhibit insulin secretion from pancreatic $\beta$-cells [21]. Therefore, the reduction of NO production may be involved in hyperinsulinemia. These data suggest the presence of a pernicious cycle of hyperinsulinemia - atherosclerosis - reduced NO production - decreased inhibitory effect of NO on insulin secretion. These findings taken together would indicate that NO plays a critical role in insulin resistance in the patients with type 2 diabetes. It remains to be clarified whether endogenous NO production is restored when insulin resistance is improved.

\section{Acknowledgments}

This study was supported in part by grants-in-aid from the Ministry of Health and Welfare, Japan, and the Ministry of Education, Science and Culture, Japan. We are indebted to Ms. Akiko Kawakami and Ms. Akiko Kanayama for secretarial help and laboratory assistance, respectively.

\section{References}

1. Laakso M, Edelman SV, Brechtel G, Baron AD (1992) Impaired insulin-mediated skeletal muscle blood flow in patients with NIDDM. Diabetes 41: 1076-1083.

2. Laakso M, Edelman SV, Brechtel G, Baron AD
(1990) Decreased effect of insulin to stimulate skeletal muscle blood flow in obese man. A novel mechanism for insulin resistance. J Clin Invest 85: 1844-1852.

3. Vallance P, Collier J, Moncada S (1989) Effects of endothelium-derived nitric oxide on peripheral ar- 
teriolar tone in man. Lancet: 997-1000.

4. Baron AD, Zhu JS, Marshall S, Irsula O, Brechtel G, Keech C (1995) Insulin resistance after hypertension induced by the nitric oxide synthesis inhibitor LNMMA in rats. Am J Physiol 269: E709-715.

5. Ferrannini E, Buzzigoli G, Bonadonna R, Giorico MA, Oleggini M, Graziadei L, Pedrinelli R, Brandi L, Bevilacqua $S$ (1987) Insulin resistance in essential hypertension. $N$ Engl J Med 317: 350-357.

6. Reaven GM (1988) Role of insulin resistance in human disease. Diabetes 37: 1595-1607.

7. Ferrannini E, Haffner SM, Mitchell BD, Stern MP (1991) Hyperinsulinemia: the key feature of a cardiovascular and metabolic syndrome. Diabetologia 34: 416-422.

8. Modan M, Halkin H, Almog S, Lusky A, Eshkol A, Shefi M, Shitrit A, Fuchs Z (1985) Hyperinsulinemia: a link between hypertension obesity and glucose intolerance. J Clin Invest 75: 809-817.

9. Paolisso G, Tagliamonte MR, Marfella R, Verrazzo G, D’Onofrio F, Giugliano D (1997) L-arginine but not D-arginine stimulates insulin-mediated glucose uptake. Metabolism 46: 1068-1073.

10. Wascher TC, Graier WF, Dittrich P, Hussain MA, Bahadori B, Wallner S, Toplak H (1997) Effects of low-dose L-arginine on insulin-mediated vasodilatation and insulin sensitivity. Eur J Clin Invest 27: 690-695.

11. Kurioka S, Koshimura K, Sugitani M, Murakami Y, Nishiki M, Kato Y (1999) Analysis of urinary nitric oxide metabolites in healthy subjects. Endocr $J 46$ : 421-428.

12. DeFronzo RA, Tobin JD, Andres R (1979) Glucose clamp technique: a method for quantifying insulin secretion and resistance. Am J Physiol 237: E214-
223.

13. Ohguni S, Notsu K, Kato Y (1995) Correlation of plasma free thyroxin levels with insulin sensitivity and metabolic clearance rate of insulin in patients with hyperthyroid Graves' disease. Intern Med 34: 339341.

14. Wennmalm Ç00A, Benthin G, Edlund A, Jungersten L, Kieler-Jensen N, Lundin S, Westfelt UN, W, Petersson AS, Waagstein F (1993) Metabolism and excretion of nitric oxide in humans. An experimental and clinical study. Circ Res 73: 1121-1127.

15. Griffith TM, Lewis MJ, Newby AC, Henderson $\mathrm{AH}$ (1988) Endothelium-derived relaxing factor. $J \mathrm{Am}$ Coll Cardiol 12: 797-806.

16. Vane JR, Änggård EE, Botting RM (1990) Regulatory functions of the vascular endothelium. $N$ Engl $J$ Med 323: 27-36.

17. McVeigh GE, Brennan GM, Johnston GD, McDermott BJ, McGrath LT, Henry WR, Andrews JW, Hayes JR (1992) Impaired endothelium-dependent and independent vasodilation in patients with type 2 (non-insulin-dependent) diabetes mellitus. Diabetologia 35: 771-776.

18. Campbell PJ, Carlson MG (1993) Impact of obesity on insulin action in NIDDM. Diabetes 42: 405-410.

19. Stout RW (1991) Insulin as a mitogenic factor: a role in the pathogenesis of cardiovascular disease. $A m J$ Med 90 (2A): 62S-65S.

20. Böger RH, Bode-Böger SM, Thiele W, Junker W, Alexander K, Frölich JC (1997) Biochemical evidence for impaired nitric oxide synthesis in patients with peripheral arterial occlusive disease. Circulation 95: 2068-2074.

21. Sjoholm A (1996) Nitric oxide donor SIN-1 inhibits insulin release. Am J Physiol 271: C1098-1102. 